УДК 557.152.3, 538.975, 621.382.3

СКоллектив авторов

АСМ-ФИШИНГ БЕЛКА В ИМПУЛЬСНОМ ЭЛЕКТРИЧЕСКОМ ПОЛЕ

\author{
Ю.Д. Иванов ${ }^{*}$, Т.О. Плешакова ${ }^{1}$ К.А. Мальсагова ${ }^{1}$, А.Л. Кайшева ${ }^{1}$, А.Т. Копьлов, А.А. Изотов \\ В.Ю. Татур ${ }^{2}$ С.Г. Веснин ${ }^{3}$ Н.Д. Иванова, В.С. Зиборов, А.И. Арчаков
}

${ }^{1}$ Институт биомедицинской химии им. В.Н. Ореховича, 119121, Москва, ул. Погодинская, 10; тел.: (7)(499)2463761; факс: (7)(499)2450857; эл. почта: yurii.ivanov@rambler.ru

${ }^{2}$ Фонд перспективных технологий и новаций, Москва ${ }^{3}$ ООО “Фирма РЭС”, Москва

${ }^{4}$ Московская государственная академия ветеринарной медицины и биотехнологии им. К.И. Скрябина, Москва ${ }^{5}$ Объединённый институт высоких температур РАН, Москва

\begin{abstract}
Комбинированный метод АСМ-фишинга и масс-спектрометрии позволяет вылавливать белковые молекулы из раствора, концентрировать и визуализировать их на атомарно-ровной поверхности АСМ-чипа, и идентифицировать с помощью масс-спектрометрического анализа. В работе предложен метод повышения эффективности АСМ-фишинга за счёт прикладывания к АСМ-чипу импульсного напряжения со временем нарастания фронта порядка одной наносекунды (нс). АСМ-чип изготовлен из проводящего материала высокоориентированного пиролитического графита (ВОПГ). Повышение эффективности АСМ-фишинга продемонстрировано на примере детекции белка цитохрома $b_{5}$. Выбор стимулирующего импульса с фронтом нарастания одна нс, соответствующим гигагерцовому диапазону частот, был обусловлен наблюдаемым нами в этом диапазоне частот эффектом излучения воды при её инъекции в измерительную ячейку.
\end{abstract}

Ключевые слова: АСМ, МС, детекция низкокопийных белков, фишинг белков

DOI 10.18097/PBMC20166204439

\section{ВВЕДЕНИЕ}

Разработка новых диагностикумов для выявления заболеваний на ранней стадии требует создания высокочувствительных методов детекции белков с фемтомолярной чувствительностью [1-3]. Под понятием “фишинг” подразумевается концентрирование белков из большого объёма раствора на небольшую зону поверхности сенсорного элемента. АСМ-фишинг - это фишинг белков на чип с последующими визуализацией и подсчётом выловленных молекул с помощью АСМ [2, 3]. Комбинация АCM-фишинга с $\mathrm{MC}$ анализом имеет большие потенциальные возможности для медицинской протеомики. Это связано с тем, что АСМ-фишинг позволяет одновременно вылавливать, концентрировать и визуализировать низкокопийные белки и их комплексы [4-8], а высокочувствительный $\mathrm{MC}$ анализ позволяет идентифицировать выловленные белки. С помощью АСМ-фишинга возможна регистрация белков в диапазоне концентраций $10^{-14}-10^{-16}$ M [2]. Такая высокая чувствительность достигается с использованием специальных методических подходов. В противном случае, чувствительность будет ниже фемтомолярной вследствие низкой скорости доставки белковых молекул в сенсорную зону на поверхности чипа [9]. Для повышения эффективности доставки молекул белка на поверхность чипа используются гидродинамические, электрические и магнитные силы [10]. Повышение эффективности за счёт гидродинамических сил реализуется обычно при использовании быстрого турбулентного режима перемешивания раствора белка $[5,11]$. Однако реализация такого подхода сопряжена с методическими трудностями, заключающимися в сложности поддержания стабильного режима перемешивания. Поэтому в настоящее время применяются методы с использованием электрических сил для повышения эффективности фишинга, например [12, 13]. Наиболее удобно использование внешнего постоянного электрического поля в электрохимических приборах, так как в этом случае не требуется специальных процедур и высокоскоростного перемешивания белкового раствора. Обычно в этом случае применяются электрические поля с очень высокой напряжённостью (несколько кВ/м) [9]. Для организации полей с такой большой напряженностью используются микрокапилляры. Однако использование микрокаппилярных систем сопряжено с трудностями их отмывки от компонентов биологической жидкости. Поэтому продолжаются исследования по разработке высокочувствительных систем, стабильно работающих в диапазоне фемтомолярных и субфемтомолярных концентраций.

Список сокращений: АCM - атомно-силовая микроскопия, атомно-силовой микроскоп, МС - масс-спектрометр, масс-спектрометрия, НИПП - наносекундное импульсное переменное поле, НССА - $\alpha$-циано-4-гидроксикоричная кислота, DHB - дигидроксибензойная кислота, ВОПГ - высокоориентированный пиролитический графит, СВЧ-диапазон - сверхвысокочастотный диапазон, ИК-диапазон - инфракрасный диапазон. 
Экспериментальные подходы на основе применения переменных электрических полей для доставки белка менее развиты, несмотря на их большой потенциал для биохимических исследований. Согласно литературным данным [12], есть возможность направленного движения частиц не только в постоянном, но и в переменном поле. Теоретически показано, что синусоидальное электрическое поле может вызывать не только флуктуации заряженных частиц относительно начального положения, но так же и направленное систематическое смещение. Электрокинетические эффекты в переменном электрическом поле, такие как диэлектрофорез и электроосмос, вызывают движение жидкости вблизи поверхности электродов [13].

В нашей работе показано, что применение импульсного переменного поля способствует повышению эффективности фишинга белка. Импульсное переменное поле создавалось в измерительной ячейке путём подачи импульсного напряжения прямоугольной формы на электрод из ВОПГ, которое имело время нарастания фронта 1 нс, частота импульса была 1 кГц и амплитуда 1 В (в дальнейшем называемое нс импульсное переменное поле, НИПП). Использование электрического поля с такими параметрами дало возможность провести фишинг белка при концентрации $10^{-15} \mathrm{M}$ из объёма 100 мл. В то же время применение переменного поля с более низким временем нарастания фронта порядка 1 мс (образованное при подаче синусоидального напряжения с частотой 1 кГц, амплитудой 1 В) или постоянного электрического поля (1 B) не приводило к фишингу белка из фемтомолярного раствора.

В нашей работе в качестве модельного белка для белкового фишинга был использован человеческий цитохром $b_{5}$. Микросомальный цитохром $b_{5}$ является мембранным белком электрон-транспортной цепи цитохрома Р450 содержащей монооксигеназной системы. Цитохром $b_{5}$ был выбран потому, что имеет очень большой заряд $(p I=4,3)$ и дипольный момент $(\sim 500 \mathrm{D})$, поэтому его взаимодействие с электрическим полем должно быть сильно выражено по сравнению с менее заряженными белками $[14,15]$. Использование АСМ в нашей работе позволило провести прямую регистрацию белка без использования меток. Другим важным достоинством предложенного подхода является то, что не требуется использования микрокапилляров и электрических полей высокой напряженности. Используемая в нашей работе напряжённость в 10-100 раз меньше, чем в микрокаппилярных системах. Выбор стимулирующего импульса с фронтом нарастания одна наносекунда (диапазон частот $\omega \leq 1$ ГГц) был обусловлен тем, что в диапазоне частот 3,4-4,2 ГГц нами наблюдалось излучение воды при инъекциях воды в ячейку. Наблюдаемое явление СВЧ излучения воды указывает на перестройку кластерной структуры воды, что в свою очередь может оказывать стимулирующее влияние на абсорбцию белка из водного раствора на поверхность чипа.

\section{МЕТОДИКА}

\section{Реактивь}

Деионизованная вода получена на установке Millipore Simplicity UV (Франция). Ацетонитрил производства "Merck" (США); стандарты калибровочных пептидов, трифторуксусная кислота, бикарбонат аммония производства "Sigma" (США); $\quad \alpha$-циано-4-гидроксикоричная кислота (HCCA), дигидроксибензойная кислота (DHB) из "Acros" (США), свиной трипсин получен от "Рromega" (Германия).

Высокоориентированный пиролитический графит (ВОПГ) получен в “НТ-МДТ” (Россия). РТFЕ плёнки

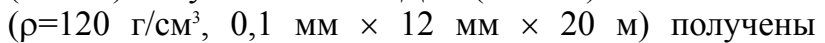
в "Tevton" (Россия).

Белки

Цитохром $b_{5}$ человека был любезно предоставлен проф. Усановым С.А. (Институт биоорганической химии НАН Беларуси).

Водные растворы белков готовили путём последовательного десятикратного разбавления исходного раствора белка $\left(10^{-9} \mathrm{M}\right)$ до необходимой концентрации с интенсивным перемешиванием на шейкере в течение 30 мин. В работе были использованы водные растворы цитохрома $b_{5}$ с концентрацией $10^{-15} \mathrm{M}$.

\section{Проиедура проведения АСМ-фитинга и оченка эффективности фишинга}

Схема лабораторной установки для АСМ-фишинга приведена на рисунке 1.

Пластину свежесколотого ВОПГ покрывали плёнкой из РТFЕ, в которой делали отверстие диаметром $\sim 200$ мкм ( $\mathrm{S} \sim 8000$ мкм $^{2}$ ). Таким образом, основная часть поверхности ВОПГ была изолирована, а в отверстии плёнки формировалась небольшая сенсорная зона. Далее пластину прижимали фторопластовой кюветой объёмом 500 мкл таким образом, чтобы поверхность ВОПГ являлась дном измерительной ячейки. Диаметр нижнего отверстия кюветы составлял 2 мм и чувствительная зона центрировалась относительно этого отверстия.

АСМ-фишинг белков проводили из водного раствора белка объёмом 100 мл. Для непрерывного ввода в ячейку раствора аналита использовали стандартный перистальтический насос, традиционно используемый в микрофлюидной технике для автоматизации экспериментов. Раствор в измерительную кювету подавали по стерильным силиконовым трубкам с внутренним диаметром $\sim 8 \mathrm{мм.}$ Скорость подачи раствора составляла 20 мкл/с. Для отбора раствора аналита из измерительной системы, в кювету вводили стерильную силиконовую трубку перистальтического насоса. Скорость отбора раствора подбирали таким образом, чтобы кювета всегда оставалась заполненной анализируемым раствором при постоянном объеме. Скорость отбора составляла также 20 мкл/с. Общее время фишинга белка из раствора составляло 1,5 ч. 


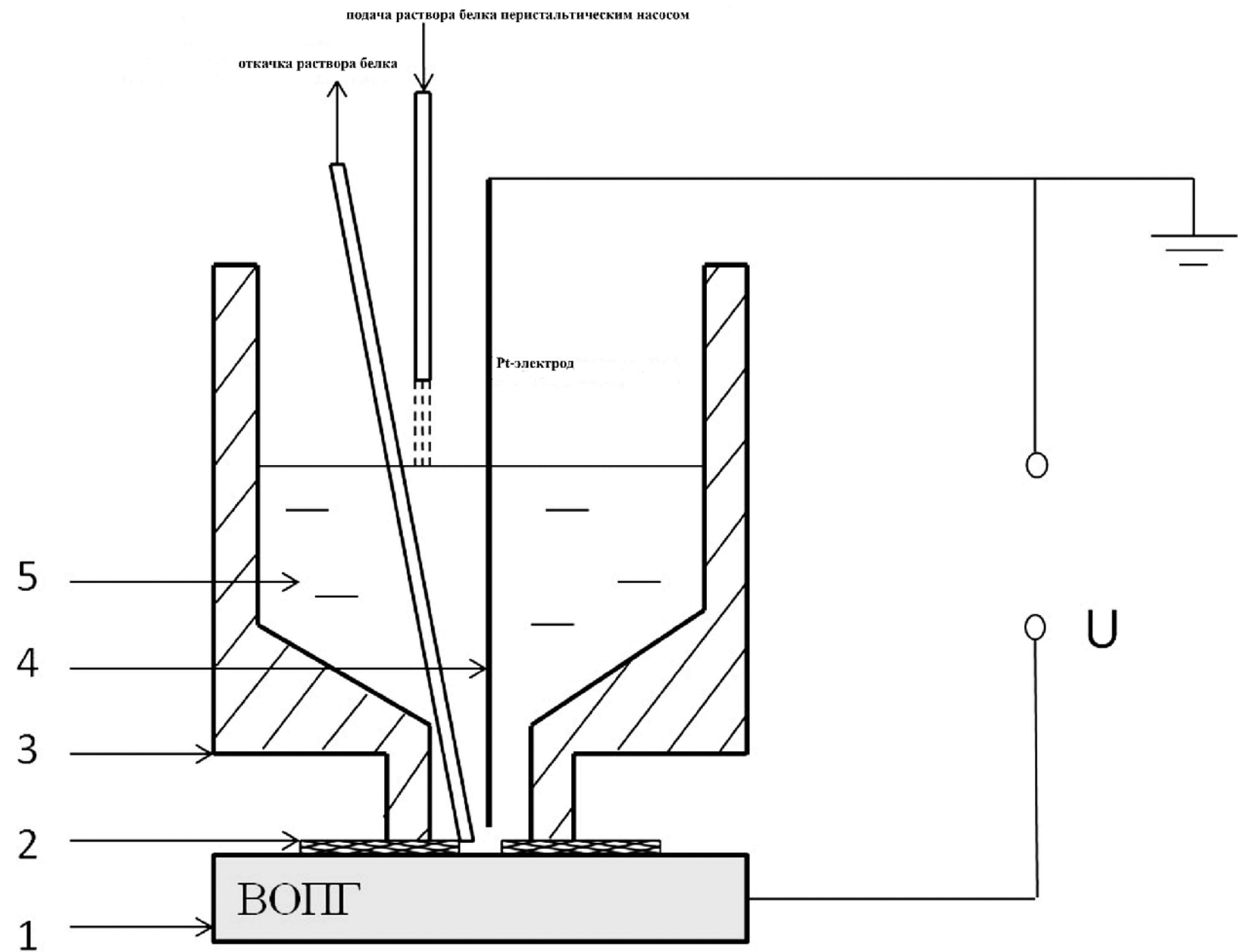

Рисунок 1. Схема лабораторной установки для АСМ-фишинга: (1) - свежесколотый ВОПГ; (2) - РТFЕ плёнка; (3) - фторуглеродная полимерная ячейка; (4) - Рt-электрод; (5) - раствор белка.

После проведения фишинга пластину ВОПГ с выловленным белком удаляли из системы и проводили АСМ-визуализацию и подсчёт выловленных объектов на поверхности ВОПГ в сенсорной зоне и МС-измерения для идентификации этих объектов.

Было исследовано влияние переменного напряжения импульсного тока прикладываемого к АCM-чипу на эффективность белкового фишинга. В этих экспериментах фишинг проводили c использованием внешнего источника напряжения и при его отсутствии. В экспериментальных сериях с использованием внешнего напряжения в кювету погружали тонкий заземлённый $\mathrm{Pt}$-электрод. Расстояние между Pt-электродом и поверхностью ВОПГ составляло 2 мм. Для электрической стимуляции процесса фишинга к ВОПГ от внешнего источника питания, являющегося одним из электродов, подавали переменное импульсное напряжение с временем нарастания фронта 1 нс длительностью 0,5 мс, наложенное на постоянное напряжение $500 \mathrm{mB}$ относительно Рt-электрода. Частота следования импульсов была 1 кГц с амплитудой $1 \mathrm{~B}$. Для исследования влияния времени нарастания фронта импульса на ВОПГ подавали модельное синусоидальное напряжение с частотой 1 кГц и амплитудой $1 \mathrm{~B}$, наложенное на постоянное напряжение 500 мВ. Напряжение поддерживалось с помощью источника питания Agilent 33220 (“Agilent”, США). В экспериментальных сериях без использования внешнего источника напряжения Pt-электрод из ячейки удаляли.

Контрольную серию экспериментов проводили аналогично методике детекции белков, однако в измерительную кювету вместо раствора белка добавляли деионизованную воду, не содержащую белка.

АСМ-визуализация и подсчет молекул белка на поверхности ВОПГ

ACM-изображения чувствительной зоны на поверхности ВОПГ после проведения фишинга белка были получены с помощью ACM Dimension 3100 (“VEECO Inc.", США) на воздухе в полуконтактном режиме с использованием ACM-зондов PPP-NCH ("Nanosensors Inc.", CША), радиус кривизны зондов не превышал 10 нм. Размер скана составлял $5 \times 5$ мкм $^{2}$, число сканов в каждой зоне не менее 10 , общая площадь сканирования каждой зоны $\mathrm{S}_{\text {scan }}=250$ мкм $^{2}$, что составляло $\sim 5 \%$ от всей площади чувствительной 
зоны ВОПГ. Анализ изображений, подсчёт количества объектов, их высот и объёмов проводили с помощью программного обеспечения обработки данных АСМ (ПО одАСМ, свидетельство о Государственной регистрации программы для ЭВМ N 2010613458).

МС идентификащия белков, выловленных на поверхность ВОПГ

Трипсинолиз белков, выловленных с помощью электрического АСМ-фишинга, проводили непосредственно на поверхности ВОПГ по стандартной схеме при постоянных температуре $42^{\circ} \mathrm{C}$ и влажности $\sim 100 \%$ [16]. Раствор для трипсинолиза содержал 100 мМ бикарбонатный буфер (pH 7,4), $10 \%$ ацетонитрил, $1 \%$ глицерол, свиной трипсин в количественном соотношении к целевому белку 1:50. После проведения трипсинолиза, триптическую смесь с пептидными фрагментами подавали на масс-анализатор для проведения идентификации белков.

Измерения проводили на хромато-массспектрометрической системе Agilent 6410 Triple Quadrupole LC/MS (“Agilent”, США), оснащенной наноэлектроспрейным источником ионизации. Для этого образцы объёмом 1 мкл подавали в нанохроматографическую колонку Zorbax C18-SB с объемом насыщения 40 нл, с размерами 75 мкм $\times 43$ мм $\times 5$ мкм. Разделение пептидов осуществляли с помощью раствора А $(0,1 \%$ муравьиная кислота в дистиллированной воде) и раствора Б (0,1\% муравьиная кислота в 90/10 ацетонитрил/ дистиллированная вода). Элюцию пептидов с хроматографической колонки проводили в градиенте раствора Б от 0 до $80 \%$ в течение 80 мин по следующей схеме: 0 мин - 5\% раствор Б, 45 мин $45 \%$ раствор Б, 60 мин - 100\%, 75 мин - 5\% раствор Б. Скорость потока через капиллярный насос была постоянна и составляла 3 мкл/мин, скорость потока через нанонасос составляла 0,3 мкл/мин. Разделение образцов проводили на наножидкостной колонке $(360$ мкм $\times 75$ мкм). Напряжение ионизации составляло 19 кВ, Q1 и Q3 разрешение составляло 0,7.

\section{Измерения излучательной способности водьl}

Измерения излучения воды по её яркостной температуре в СВЧ и ИК диапазонах были проведены при её инъекции в ячейку, наполненную водой. Для измерения излучения в инфракрасном (8-13 мкм) и гигагерцовом диапазоне (3,4-4,2 Ггц) использовали радиотермометр RTM-01 RES (Россия). Для измерения в гигагерцовом диапазоне использовали штыревую антенну, соединённую с радиотермометром. Погрешность измерения температуры составляла $0,1^{\circ} \mathrm{C}$.

\section{РЕЗУЛЬТАТЫ И ОБСУЖДЕНИЕ}

\section{Результаты контрольных экспериментов}

проведенных без приложенного электрического поля

Две контрольные серии экспериментов по определению содержания неспецифических объектов, сорбированных на ВОПГ, проводили по методике АСМ-фишинга, описанной в разделе “Методика". Первая серия контрольных экспериментов была проведена с очищенной водой.

В процессе непрерывной подачи очищенной воды перистальтическим насосом в течение 3 ч на поверхности ВОПГ сорбируется большое количество неспецифических объектов высотой 3-5 нм (данные не представлены). МС-анализ этих объектов не выявил пептидных фрагментов. Следовательно, можно сделать вывод, что появление этих объектов было связано с неспецифической сорбцией частиц, присутствующих в системе. При уменьшении времени проведения экспериментов по прокачке воды в одних и тех же проводящих трубках до 1,5 ч сорбции неспецифических объектов высотой 3-5 нм не наблюдается. Поэтому, это время было выбрано для проведения фишинга.

Вторая серия контрольных экспериментов была проведена при подаче раствора белка в измерительную ячейку без использования электрического поля. В этих условиях не было зарегистрировано объектов высотой более чем 0,3 нм с помощью АCM. MC анализ образцов с поверхности ВОПГ в этих экспериментах не показал наличие пиков, соответствующих пептидным фрагментам.

\section{Детекция ичитохрома $b_{5}$ на ВОПГ \\ с помощьью АСМ-фишинга}

АСМ фишинг цитохрома $b_{5}$ в постоянном электрическом поле (без приложенного переменного электрического поля). АСМ фишинг цитохрома $b_{5}$ из раствора на поверхность ВОПГ был проведён в постоянном электрическом поле при постоянном напряжении +1 B. В этих условиях фишинга на поверхности не наблюдались объекты высотой более 1 нм (рис. 2B).

АСМ фишинг цитохрома $b_{5}$ в импульсном электрическом поле. Перед экспериментами по электрической стимуляции АCM-фишинга был проведён выбор частотного диапазона прикладываемого напряжения электрического поля. Он был основан на следующих результатах. При инъекции воды наблюдается собственное излучение в диапазоне $3,4-4,2$ ГГц с соответствующим изменением яркостной температуры с $21,7^{\circ} \mathrm{C}$ до $22,1-22,3^{\circ} \mathrm{C}$. При проведении измерений в инфракрасном диапазоне яркостная температура $\mathrm{T}_{\text {ик }}$ при этом снижалась, примерно на $1^{\circ} \mathrm{C}$. Появление собственного излучения в гигагерцовом диапазоне может быть связано с перестройкой кластерной структуры воды при её инъекции вблизи фазового перехода (в этой области наблюдается фазовый переход, связанный с поверхностным натяжением воды [17]). В свою очередь, изменения кластерной структуры воды могут вызывать реорганизацию гидратной оболочки белка, что в конечном итоге способствует сорбции молекулы белка на поверхность чипа. Поэтому для повышения эффективности АСМ-фишинга мы использовали стимулирующее электрическое поле с нс фронтом нарастания, что соответствует гигагерцовому диапазону частот ( $\geq 1$ ГГц). 


\section{Иванов и др.}

Результаты АСМ-фишинга в импульсном электрическом поле показали, что на поверхности ВОПГ наблюдались объекты, которые отсутствовали в контрольных экспериментах без электрической активации или в присутствии только постоянного электрического поля (рис. 2А). Эти объекты имели некомпактную протяженную форму с максимумом высоты визуализированных объектов $h_{\max }=1,4 \pm 0,2$ нм (рис. 2Б). Количество этих объектов составляло 2700 на площадь сканирования. В контрольных экспериментах, при анализе растворов, не содержащих белок, сорбции таких частиц не наблюдалось.

АСМ-фишинг цитохрома $b_{5}$ в переменном синусоидальном электрическом поле. Как было показано в предыдущем разделе, наблюдалась стимуляция АСМ-фишинга цитохрома $b_{5}$ при подаче на ВОПГ электрических импульсов с фронтом нарастания 1 нс, частотой повторения импульсов 1 кГц и продолжительность импульсов 0,5 мс. Для выявления влияния фронта нарастания импульсов на эффективность АСМ-фишинга в работе на ВОПГ подавалось переменное синусоидальное напряжения с такой же частотой 1 кГц и амплитудой 1 В вместо импульсного напряжения. Это синусоидальное напряжение было наложено на постоянное напряжение. Фронт нарастания такого синусоидального напряжения был порядка $\tau_{\gamma}=1 / 2 \omega=1 /(2 \times 1$ кГц $)=5 \times 10^{-3} \mathrm{c}$. Это много больше, чем 1 нс для нс импульсов. Измерения, проведенные при использовании синусоидального напряжения, показали, что на поверхности чипа не вылавливались объекты с высотой более чем 0,3 нм. Таким образом, использование синусоидального напряжения не повышало эффективность АСМ-фишинга цитохрома $b_{5}$, в отличие от импульсного напряжения.
A

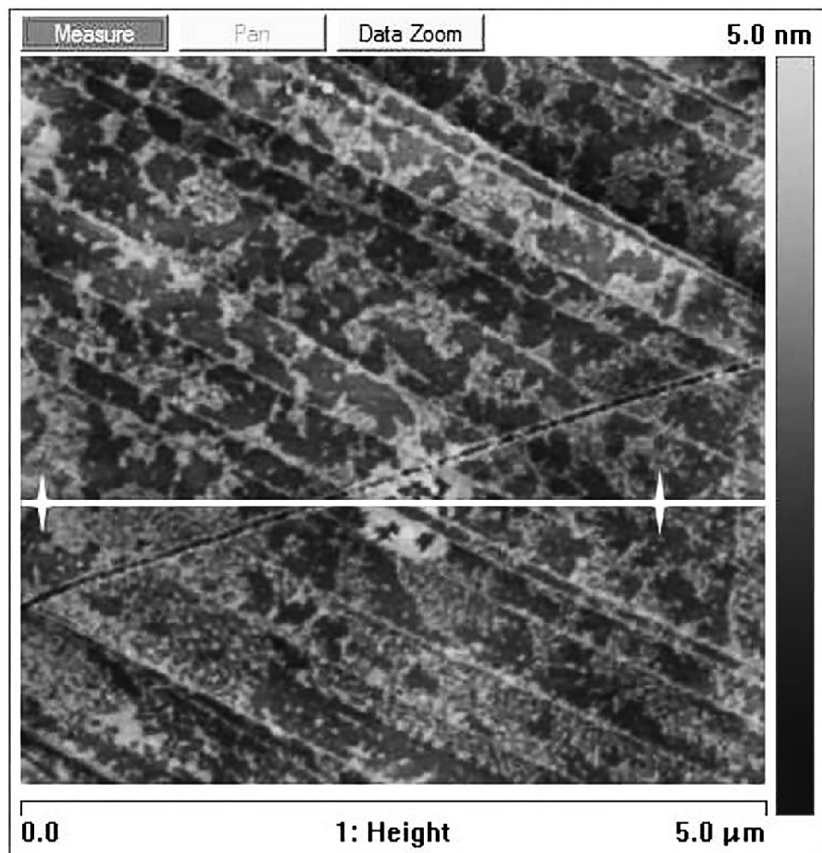

B

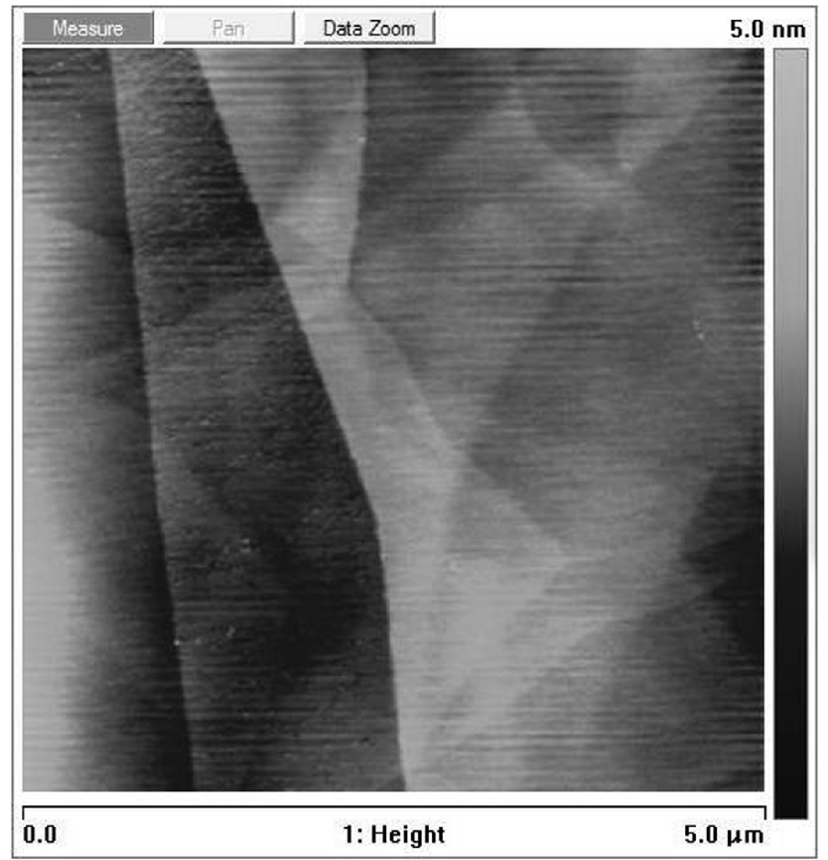

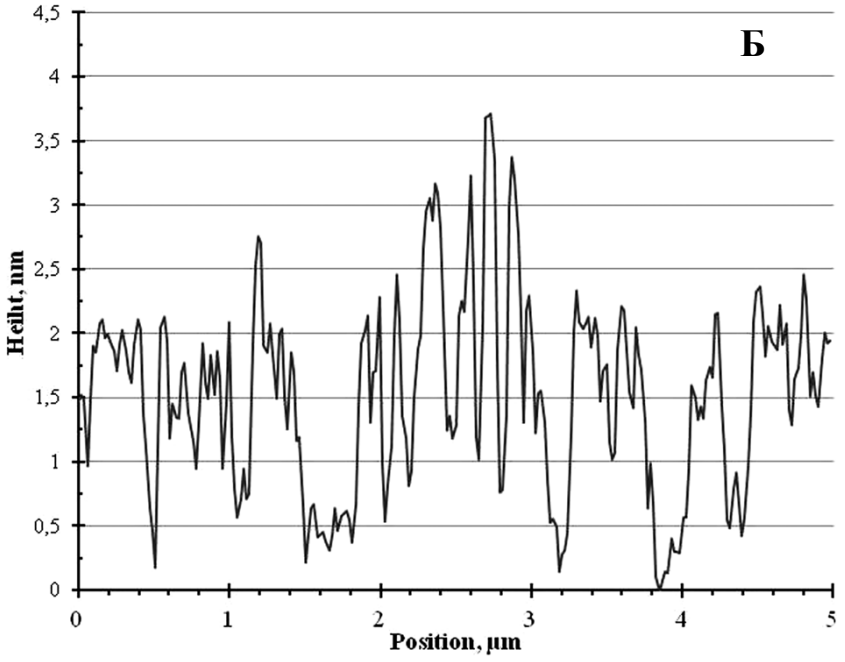

Рисунок 2. Пример АСМ скана, полученного с поверхности ВОПГ после фишинга цитохрома $b_{5}$ в НИПП (А) и соответствующее сечение (белая линия, Б). Пример АСМ скана, полученного в контрольных экспериментах при фишинге белка в постоянном электрическом поле (В). Экспериментальные условия: размер скана 5 мкм $\times 5$ мкм, шкала $\mathrm{Z}$ от 0 нм до 5 нм, концентрация белка $10^{-15} \mathrm{M}$. 
MC-идентификация цчитохрома $b_{5}$, выловленного на поверхность ВОПГ с помощьюю АСМ-фишинга

В результате предварительных МС-измерений, проведенных для трипсинолизата коммерческого препарата цитохрома $b_{5}\left(\begin{array}{lll}10^{-7} & \mathrm{M})\end{array}\right.$ в режиме сканирования в диапазоне $\mathrm{m} / z \quad 400-1200$ были отобраны два уникальных пептида цитохрома $b_{5}$ и 5 фрагментов для каждого с наибольшими значениями интенсивности на хроматограмме. Для пептида YYTLEEIQK были отобраны фрагменты для мониторинга со значениями $m / z 541,27,517,30,512,27,670,31,430,74$; для пептида EQAGGDATENFEDVGHSTDAR были отобраны фрагменты со значениями $\mathrm{m} / z$ 543,74, 617,28, 462,23, $859,34,1086,48$.

Масс-спектрометрические измерения в режиме мониторинга множественных реакций образцов ВОПГ после АСМ-фишинга цитохрома $b_{5}$ из раствора c концентрацией $10^{-15} \mathrm{M}$ позволили выявить целевой белок по двум его уникальным пептидам (рис. 3). Были обнаружены четыре фрагмента для пептида YYTLEEIQK (время выхода 19,5 мин) $\mathrm{m} / z \quad 593,80$ и три фрагмента для пептида EQAGGDATENFEDVGHSTDAR (время выхода 4,0 мин) $\mathrm{m} / \mathrm{z} 735,98$ (рис. 3Б,В).
На рисунке 3 приведены данные МС-измерений, полученные при идентификации объектов, выловленных с помощью АСМ-фишинга из раствора с концентрацией $10^{-15} \mathrm{M}$ с электрической стимуляцией прямоугольными наносекундными импульсами. Масс-спектры для полученных пептидов соответствовали цитохрому $b_{5}$.

Результаты МС-анализа образцов во всех контрольных экспериментах без применения электрической стимуляции, а также с электрической стимуляцией постоянным напряжением и напряжением синусоидальной формы (см п.3.1.1 - 3.2.3) показали, что для этих условий на поверхности ВОПГ пептиды цитохрома $b_{5}$ не были обнаружены.

\section{ОБСУЖДЕНИЕ}

В микрожидкостных системах с низкой скоростью прокачивания белкового раствора не достигается высокая концентрационная чувствительность, обусловленная только механизмом Броуновского движения. Для наших экспериментальных условий время фишинга, определяемое исключительно Броуновским движением, составляет порядка $\mathrm{t}=\mathrm{h}^{2} / 2 \mathrm{D}=0,2^{2} / 2 \times 10^{-6}=2 \times 10^{8}(\mathrm{c})$, где $\mathrm{D}-$ коэффициент диффузии, равный $10^{-6} \mathrm{~cm}^{2} \cdot \mathrm{c}^{-1}$. За 1,5 ч не должно

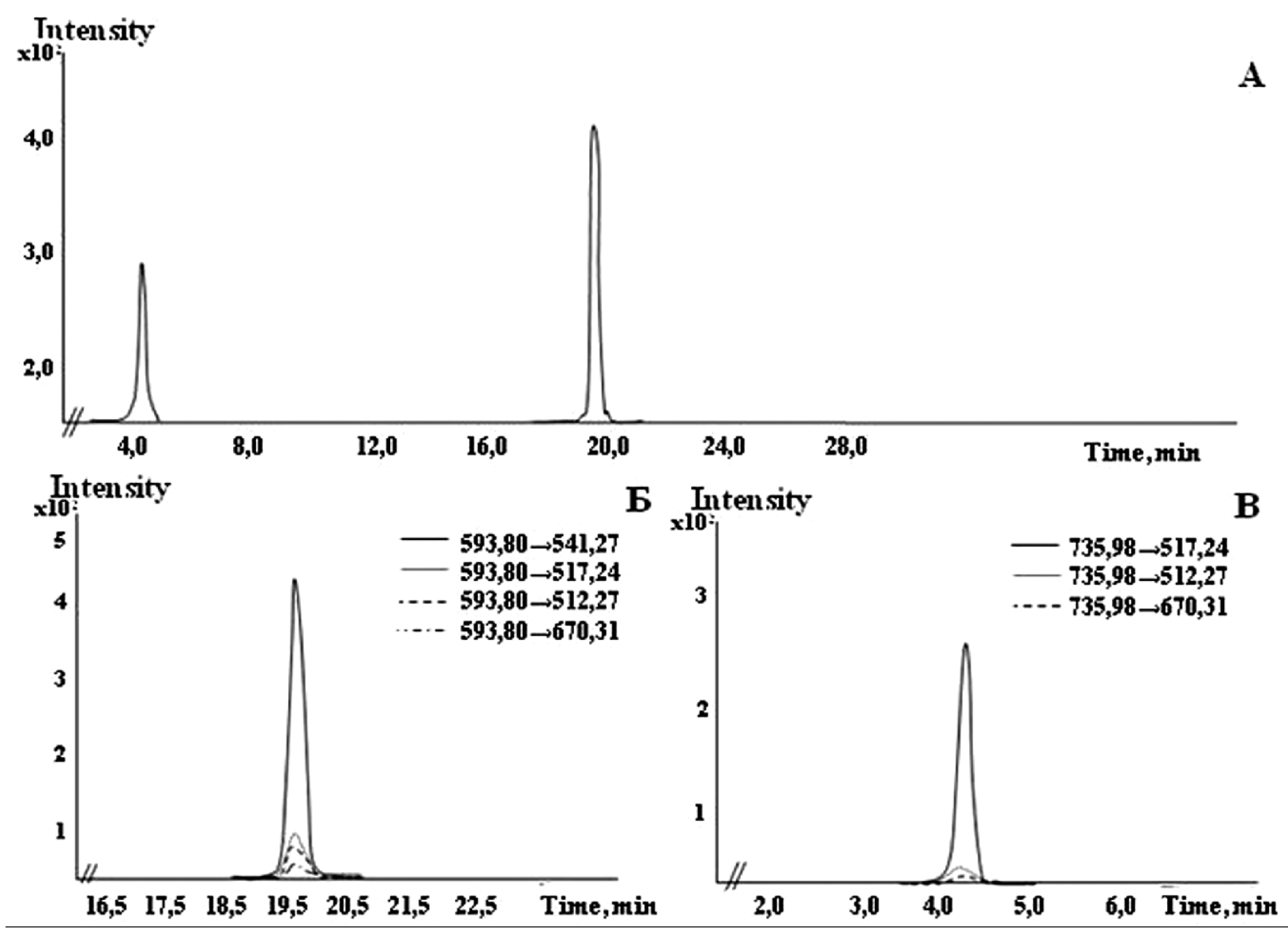

Рисунок 3. Хроматограмма полного ионного тока для цитохрома $b_{5}(\mathrm{~A})$. Пример результата измерения образца после АСМ-фишинга цитохрома $b_{5}$ на поверхность ВОПГ из раствора концентрацией $10^{-15} \mathrm{M} \mathrm{в} \mathrm{НИПП.} \mathrm{Проводился}$ мониторинг двух пептидов цитохрома $b_{5}$ и пяти фрагментов для каждого. Обнаружены четыре фрагмента для пептида YYTLEEIQK (время выхода 19,5 мин) $\mathrm{m} / \mathrm{z}$ 593,80 (Б), и три фрагмента для пептида EQAGGDATENFEDVGHSTDAR (время выхода 4,0 мин) $\mathrm{m} / z$ 735,98 (В). 
быть выловлено молекул цитохрома $b_{5}$. Действительно, в наших экспериментах без использования электрического поля не удалось зарегистрировать белковых молекул на поверхности АСМ-чипа с помощью АСМ и МС. В тоже время, использование электрического поля, должно понижать время фишинга белка. Теоретические оценки, основанные на использование стандартных уравнений для электрофореза, показывают, что в наших экспериментальных условиях $\left(\mathrm{V}_{0}\right.$ ячейки $=100$ мл, $\mathrm{C}$ белка $=10^{-15} \mathrm{M}$, диаметр чувствительной зоны ACM-чипа 200 мкм, постоянное напряжение $U=1$ В) количество молекул белка, которое может быть выловлено на поверхность АСМ чипа, составляет 22100 [8]. Принимая во внимание, что площадь АСМ-сканирования составляла $5 \%$ полной площади чувствительной зоны ВОПГ, можно предположить, что число молекул, которое обнаруживается методом АCM, должно составлять 250. Отметим, что количество молекул белка на поверхности ВОПГ, необходимое для регистрации методом АCM, составляет не менее 500 молекул на площади 400 мкм $^{2}$ $[2,3,5]$, а методом МC - не менее $10^{4}[18,19]$.

Соответственно, такое число молекул белка (250) недостаточно ни для АСМ регистрации, ни для МC анализа. Данные, полученные при АСМ сканировании поверхности ВОПГ после проведения фишинга белка с электрической стимуляцией нс импульсным электрическим полем, показали повышение эффективности вылавливания белка из раствора. Электрическая стимуляция была проведена прямоугольными нс импульсами (то есть импульсами с фронтом нарастания $\tau=1 \mathrm{нc}$ ). Импульсы такой формы могут быть представления в виде ряда Фурье, то есть сумма синусоидальных сигналов с основным вкладом гармоники, имеющих частоту $\mathrm{f} \sim 1 / \tau=1$ ГГц $=1000$ МГц. В тоже время, результаты АCM сканирования после фишинга в присутствии синусоидального электрического поля с частотой 1 кГц, показали, что такое поле с $\tau \sim 1$ мс не приводит к увеличению эффективности АСМ-фишинга. Таким образом, можно сделать вывод, что повышение эффективности АСМ-фишинга наблюдается при стимуляции электрическим полем с высокой скоростью нарастания фронта (порядка 1 нс). Применение переменного электрического поля для изучения диффузии молекул обсуждалось в литературе $[13,20]$. В работе [20] переменное электрическое поле способствовало концентрированию молекул на золотом электроде. При этом эффективность концентрирования молекул в центре электрода нелинейно зависела от частоты электрического поля. Наибольший эффект концентрирования молекул в центре электрода наблюдался при частоте 10 кГц. В нашей работе, стимуляция АСМ-фишинга переменным электрическим полем наблюдалась при фронте его изменения порядка 1 нс. В тоже время напряжённость поля была в 10-100 раз меньше, чем значения, которые обычно используются в микрожидкостной технике. Такая импульсная электрическая стимуляция процесса АСМ-фишига, возможно, связана с изменением кластерной структуры воды и, соответственно, гидратной оболочки белковой глобулы, возбуждением белковой молекулы, изменением ВОПГ поверхности АСМ чипа (например, изменение кластерной структуры воды на гидрофобной поверхности графита) и другими электрокинетическими эффектами. На изменение кластерной структуры воды указывает появление СВЧ-излучения, зарегистрированное в гигагерцовом диапазоне. Это явление может наблюдаться не только в системе, рассматриваемой в данной работе, но и в других аналитических системах, связанных с вводом водных растворов, в частности, в нанопроводных устройствах. Кроме того, оно может оказывать значительный эффект на результаты измерений в аналитических системах. Отметим, что обнаруженная нами генерация неравновесного СВЧ-излучения водной среды при её механическом возбуждении должна наблюдаться также и в живых организмах, имеющих кровеносную систему, так как в них также происходит механическое возбуждение водного раствора - крови - как при работе сердца, инжектирующего кровь в сосудистую систему, так и при движении крови по сосудам. При этом, в свою очередь, появляющееся СВЧ-излучение влияет на биохимические процессы, протекающие в организме.

\section{ЗАКЛЮЧЕНИЕ И ВЫВОДЫ}

Показано, что одним из определяющих факторов для эффективной доставки белка в процессе АСМ-фишинга является скорость нарастания фронта электрического поля в измерительной ячейке. Продемонстрировано, что импульсное электрическое поле с фронтом нарастания 1 нс приводит к повышению эффективности доставки белка. В то же время, меньшее время изменения нарастания фронта электрического поля (порядка 1 мс) не приводило к эффективному фишингу белка на поверхность ВОПГ. Возможность метода с импульсной электрической стимуляцией АСМ-фишинга продемонстрирована в экспериментах с цитохромом $b_{5}$. Этот белок был выловлен из 100 мл белкового раствора при концентрации $10^{-15} \mathrm{M}$.

Работа была выполнена при поддержке гранта РФФИ 15-04-08368.

\section{ЛИТЕРАТУРА}

1. Rissin D., Kan C., Campbell T., Howes S., Fournier D., Song L., Piech T., Patel P., Chang L., Rivnak A., Ferrel E., Randall J., Provuncher G., Walt D., Duffy D. (2010) Nature Biotech., 28, 595-599.

2. Archakov A., Ivanov Y., Lisitsa A., Zgoda V. (2007) Proteomics, 7, 4-9.

3. Archakov A., Ivanov Y., Lisitsa A., Zgoda V. (2009) Proteomics, 9, 1326-1343.

4. Ivanov Y., Bukharina N., Frantsuzov P., Pleshakova T., Kanashenko S., Medvedeva N., Argentova V., Zgoda V., Munro A., Archakov A. (2012) Soft Matter, 8, 4602-4608.

5. Ivanov Y., Danichev V., Pleshakova T., Shumov I., Ziborov V., Krokhin N., Zagumenniy M., Ustinov V., Smirnov L., Shironin A., Archakov A.I. (2014) Biomed. Khim, 60, 28-56. 
6. Ivanov Y., Bukharina N., Frantsuzov P., Pleshakova T., Krohin N., Kanashenko S., Archakov A. (2013) Biomed. Khim, 59,378-387.

7. Ivanov Y., Bukharina N., Pleshakova T., Frantsuzov P., Krokhin N., Ziborov V., Archakov A. (2011) J. Biophys., 56, 892-896.

8. Ivanov Y., Pleshakova T., Malsagova K., Kozlov A., Kaysheva A., Kopylov A., Izotov A., Andreeva E.Y., Kanashenko S., Usanov S., Archakov A. (2014) FEBS J., 281, 4705-4717.

9. Morozov V., Groves S., Turell M., Bailey C. (2007) J. Am. Chem. Soc., 129, 12628-12629.

10. Wong P., Wang T., Deval J., Ho C. (2004) IEEE/ASME Trans. Mechatronics, 9, 366-376.

11. Haas $P$. Then $P$., Wild A., Grange $W$. Zorman $S$, Hegner $M$. Calame M., Aebi U., Flammer J., Hecht B. (2010) Anal. Chem., 82, 6299-6302.

12. Bolotskii B., Serov A. (1994) Physics-Uspekhi, 37, 515-517.
13. Ramos A., Morgan H., Green N., Castellanos A. (1998) J. Phys. D: Appl. Phys., 31, 2338-2353.

14. Dixon D., Hong X., Woehler S. (1989) J. Biophys., 56, 339-351.

15. Abe K., Sugita Y. (1979) Eur. J. Biochem., 101, 423-428.

16. Кайшева А.А., Иванов Ю.Д., Згода В.Г., Франиузов П.А., Плешакова Т.О., Крохин Н.В., Зиборов В.С., Арчаков А.И. (2010) Биомед. химия, 56, 26-39.

17. Першин С., Бункин А., Лукьянченко В.А. (2009) $\mathrm{V}$ Международный конгресс "Слабые и сверхслабые поля и излучения в биологии и медицине”, сc. 87-97. IBSN: 5-86456-007-3

$18 \mathrm{http}: / /$ www.rhupo.ru/doc/autoflex.pdf

19. http://www.chem.agilent.com/Library/applications/ 5991-2729EN.pdf

20. Wong P., Chen C., Wang T., Ho C. (2004) Anal. Chem., 76, 6908-6914.

Поступила: $\quad$ 01. 09. 2014.

\title{
AFM FISHING OF PROTEINS UNDER IMPULSE ELECTRIC FIELD
}

\author{
Yu.D. Ivanov', T.O. Pleshakova', K.A. Malsagova', A.L. Kaysheva', A.T. Kopylov ${ }^{1}$, A.A. Izotov', V.Yu. Tatur ${ }^{2}$, \\ S.G. Vesnin', N.D. Ivanova , V.S. Ziborov ${ }^{5}$, A.I. Archakov ${ }^{1}$ \\ ${ }^{1}$ Institute of Biomedical Chemistry, \\ 10 Pogodinskaya str., Moscow, 119121 Russia; tel.: (7)(499)2463761; fax: (7)(499)2450857; \\ e-mail: yurii.ivanov@rambler.ru \\ ${ }^{2}$ Foundation of Perspective Technologies and Innovations, Moscow, Russia \\ ${ }^{3}$ RES LTD. Moscow, Russia \\ ${ }^{4}$ Skryabin Moscow State Academy of Veterinary Medicine and Biotechnjlogy (FSGEI of HPE), Moscow, Russia \\ ${ }^{5}$ Joint Institute for High Temperatures of RAS, Moscow, Russia
}

A combination of (atomic force microscopy)-based fishing (AFM-fishing) and mass spectrometry allows to capture protein molecules from solutions, concentrate and visualize them on an atomically flat surface of the AFM chip and identify by subsequent mass spectrometric analysis. In order to increase the AFM-fishing efficiency we have applied pulsed voltage with the rise time of the front of about $1 \mathrm{~ns}$ to the AFM chip. The AFM-chip was made using a conductive material, highly oriented pyrolytic graphite (HOPG). The increased efficiency of AFM-fishing has been demonstrated using detection of cytochrome $b_{5}$ protein. Selection of the stimulating pulse with a rise time of $1 \mathrm{~ns}$, corresponding to the $\mathrm{GHz}$ frequency range, by the effect of intrinsic emission from water observed in this frequency range during water injection into the cell.

Key words: AFM, MS, detection of low-copied proteins, protein fishing 